\title{
Structural, Morphological, Optical and Electrical properties of Schottky diodes based on CBD deposited ZnO:Cu Nanorods
}

Benard S. Mwankemwa ${ }^{1,2^{*}}$, Matshisa J. Legodi ${ }^{1}$, Mbuso Mlambo ${ }^{1}$, Jackie M. Nel ${ }^{1}$ and Mmantsae Diale $^{1}$

${ }^{1}$ Department of Physics, University of Pretoria, Private bag X20, Hatfield, Republic of South Africa.

${ }^{2}$ Department of Physics, School of Physical Sciences, College of Natural and Mathematical Sciences, University of Dodoma, P. O. Box 338, Dodoma, Tanzania.

*Corresponding author: benard_80@yahoo.com

\begin{abstract}
Undoped and copper doped zinc oxide $(\mathrm{ZnO})$ nanorods have been synthesized by a simple chemical bath deposition (CBD) method at a temperature of $90{ }^{\circ} \mathrm{C}$. Structural, morphological, optical and electrical properties of the synthesized $\mathrm{ZnO}$ nanorods were found to be dependent on the $\mathrm{Cu}$ doping percentage. X-ray diffraction (XRD) patterns revealed strong diffraction peaks of hexagonal wurtzite of $\mathrm{ZnO}$, and no impurity phases from metallic zinc or copper. Scanning electron microscopy (SEM) images showed changes in diameter and shape of nanorods, where by those doped with 2 at.\% and 3 at.\% aggregated and became compact. Selected area electron diffraction (SAED) patterns indicates high quality, single crystalline wurtzite structure $\mathrm{ZnO}$ and intensities of bright spots varied with copper doping concentration. UV-visible absorption peaks of $\mathrm{ZnO}$ red shifted with increasing copper doping concentration. Raman studies demonstrated among others, strong and sharp $\mathrm{E}_{2}$ (low) and $\mathrm{E}_{2}$ (high) optical phonon peaks confirming crystal structure of $\mathrm{ZnO}$. Current-voltage measurements based on the gold/ZnO nanorods/ITO showed good rectifying behavior of the Schottky diode. The predicted Schottky barrier height of $0.60 \mathrm{eV}$ was obtained which is not far from the theoretical Schottky-Mott value of $0.80 \mathrm{eV}$.

Keywords: Zinc oxide nanorods, chemical bath deposition, Structural properties, Electron microscopy, Electrical properties
\end{abstract}




\section{Introduction}

Zinc oxide $(\mathrm{ZnO})$ is one of the important metal oxides semiconductors especially in nanostructured form due to its potential applications in solar cells, optoelectronic, piezoelectric and ferromagnetic devices [1-7]. It is an intrinsic $n$-type semiconductor characterized by having highly desirable electrical and optical properties. Consequently, it is a versatile, functional material, and exhibits a wide range of structural morphologies. Amongst these morphologies, one-dimensional (1D) nanostructures, mainly nanowires, nanorods, nanofibres, nanobelts and nanotubes were found to be the most promising [8-12].

Suitability for doping in $\mathrm{ZnO}$ lattice attracted research on the same and properties like ferromagnetism, gas sensing, enhancement of photocatalytic activity, optical and electrical properties were reported to be improved after doping [13-15]. Recently metal doping especially copper $(\mathrm{Cu})$ into $\mathrm{ZnO}$ structure is thoroughly investigated due to several advantages including low formation energy and its smaller ionization potential which boost the incorporation of it into the host lattice [16,17]. Additionally, it is proved that $\mathrm{Cu}$ doping modifies the luminescence of $\mathrm{ZnO}$ due to the formation of localized impurity levels [17-19]. Besides the difference in the ionic radii, physical and chemical properties of $\mathrm{Cu}$ and $\mathrm{Zn}$ are much related and thus substituting $\mathrm{Zn}$ sites without changing the hexagonal wurtzite structure of $\mathrm{ZnO}$. Generally, $\mathrm{Cu}$ doping enhances the properties of $\mathrm{ZnO}$ without affecting its crystal structure.

Several reports have focused on synthesis and properties of $\mathrm{Cu}$ doped $\mathrm{ZnO}$ in thin films and nanostructures forms [20-23]. Othman et al. [23] found that incorporation of $\mathrm{Cu}$ led to an increase in electrical conductivity. Agarwal et al [24] reported on the spin coated $\mathrm{Cu}$ doped $\mathrm{ZnO}$ films on silicon substrate based Schottky diodes, where a $\mathrm{Cu}$ doped sample presented improved 
diode performance. From their study, only one doping concentration of 5.0 mol\% was investigated.

Systematic studies on the effect of $\mathrm{Cu}$ doping on electrical properties of $\mathrm{ZnO}$ nanorods based on Schottky diodes are limited in the literature especially those reported on conducting indium tin oxide (ITO) substrate as ohmic contact. In the present study, we synthesized $\mathrm{ZnO}$ nanostructures using a chemical bath deposition (CBD) method. Together with structural, morphological and optical properties studied as a function of $\mathrm{Cu}$ doping, electrical properties of gold $(\mathrm{Au}) / \mathrm{ZnO}$ nanorods/ITO Schottky diode structure were studied using current-voltage $(I-V)$ measurements. Through repeated measurements on different Schottky contact points, we found that $\mathrm{Cu}$ doping positively improved rectification behavior of the Schottky diodes. In addition, the contrast between forward and reverse current is about four orders of magnitude, indicating improved performance of the device.

\section{Experimental Procedures}

Undoped and $\mathrm{Cu}$ doped $\mathrm{ZnO}$ nanorods have been synthesized on indium tin oxide (ITO) substrate seed-layer assisted CBD. Before deposition of nanorods, the substrates were thoroughly cleaned using warm soap solution, rinsed using deionized (DI) water, followed by acetone, ethanol and DI water by sonication for 5 minutes each. The gel were prepared by dissolving appropriate amount of zinc acetate dihydrate $\left(\mathrm{Zn}\left(\mathrm{CH}_{3} \mathrm{COO}\right)_{2} \cdot 2 \mathrm{H}_{2} \mathrm{O}\right.$, Merck) in $10 \mathrm{ml}$ of ethanol giving $35 \mathrm{mM}$ solution which were aged for $24 \mathrm{~h}$. Cleaned ITO substrates partly covered using a non-sticking heat resistant tape were spin-coated at $3000 \mathrm{rpm}$ for $1 \mathrm{~min}$ to form $\mathrm{ZnO}$ seed layer which was then dried in air. The above procedure was done three times in order to increase thickness of $\mathrm{ZnO}$ seed layer. Finally, the spin coated $\mathrm{ZnO}$ seed layer was annealed in an oven at 
$350^{\circ} \mathrm{C}$ for $60 \mathrm{~min}$. The growth solution of the nanorods was prepared by dissolving equimolar amounts $(35 \mathrm{mM})$ of zinc nitrate hexahydrate $\left(\mathrm{Zn}\left(\mathrm{NO}_{3}\right)_{2} \cdot 6 \mathrm{H}_{2} \mathrm{O} ; 98 \%\right.$, Sigma) and hexamethylenetetramine (HMT; $99.5 \%$, Sigma) in DI water. For doping, 1, 2 and 3 at.\% of $\mathrm{Cu}\left(\mathrm{NO}_{3}\right)_{2} \cdot 6 \mathrm{H}_{2} \mathrm{O}$, Sigma) was added in the reaction mixture under constant stirring at room temperature for $60 \mathrm{~min}$ so as to allow all the constituent to dissolve completely. The nanorods growth was accomplished by suspending substrates with the seeded surface facing downwards (using non-releasable nylon cable ties) in the beaker containing the growth solution. The beaker was then placed in a water bath at $90^{\circ} \mathrm{C}$ with an error of \pm 1 for $60 \mathrm{~min}$. The temperature was then maintained constant throughout the experiment. After the growth, the substrates were immediately removed from the growth beaker, washed with DI water and annealed at $350^{\circ} \mathrm{C}$ for $30 \mathrm{~min}$. The initially covered part of the ITO was used as an Ohmic contact while $100 \mathrm{~nm}$ circular $\mathrm{Au}$ metal were deposited on the $\mathrm{ZnO}$ face of the annealed samples using resistive vacuum deposition at a deposition rate of $1 \AA / s$ and were used as Schottky contacts.

The crystallographic properties of the nanorods were evaluated using Rugaku SmartLab X-ray Difractometer (XRD). The surface morphology of the nanorods were studied using field emission scanning electron microscopy (FE - SEM, ZEISS SEM-Microscopes Crossbeam|540) and high-resolution transmission electron microscope (HRTEM) JOEL JEM-2100, a multipurpose $200 \mathrm{kV}$ analytical electron microscope. For TEM analysis, $\mathrm{ZnO}$ powder was scratched from the substrate having $\mathrm{ZnO}$ nanorods, dispersed in ethanol and sonicated for $30 \mathrm{~min}$ before was put on copper grid. Optical absorption of the films was measured at RT using a PASCO Spectrometer, PS-2600 (PASCO scientific). RT Raman studies were performed using 
Horiba Jobin Yvon micro Raman. Electrical properties of the Schottky diode were measured at RT using SMU (Key sight B2912A) Keithley 230 meter.

\section{Results and Discussion}

\subsection{Structural and Morphological Results}

The XRD patterns of undoped and $\mathrm{Cu}$ doped $\mathrm{ZnO}$ studied using $\mathrm{Cu}-\mathrm{K} \alpha_{1}$ radiation are presented in Fig. 1. All the patterns revealed crystalline structure of the samples with peaks indexed to (100), (002), (101), (102), (110), (103), (200), (112), (201) and (202) planes matching the characteristic hexagonal wurtzite structure of bulk $\mathrm{ZnO}$, Fig. 1(a). The absence of extra peaks from $\mathrm{Cu}$, nitrate or any other impurity confirms the purity of the obtained nanorods. The intensity and full width at half maximum (FWHM) of (100) and (101) planes were found to significantly change with increasing $\mathrm{Cu}$ doping as seen in Fig. 1 (b). The observed changes are due to the effects of incorporation of $\mathrm{Cu}$ into the $\mathrm{ZnO}$ lattice and thus changes crystallographic properties of the obtained nanorods. Apart from changes in the intensities and FWHM, plane direction intensities also changes as the $\mathrm{Cu}$ doping concentration was increased. The 3 at $\% \mathrm{Cu}$ doped $\mathrm{ZnO}$ nanorods show the highest (100) and (101) peak intensities compared to 2 at $\%, 1$ at $\%$ and undoped. It is clear from this result that the presence of $\mathrm{Cu}$ doping favours (100) and (101) directions while weakening the (002) plane as it decreased with addition of $\mathrm{Cu}$. The lattice

parameters $a$ and $c$ calculated from (100) and (002) planes, respectively using equation 1 and 2 are shown in Table 1. 

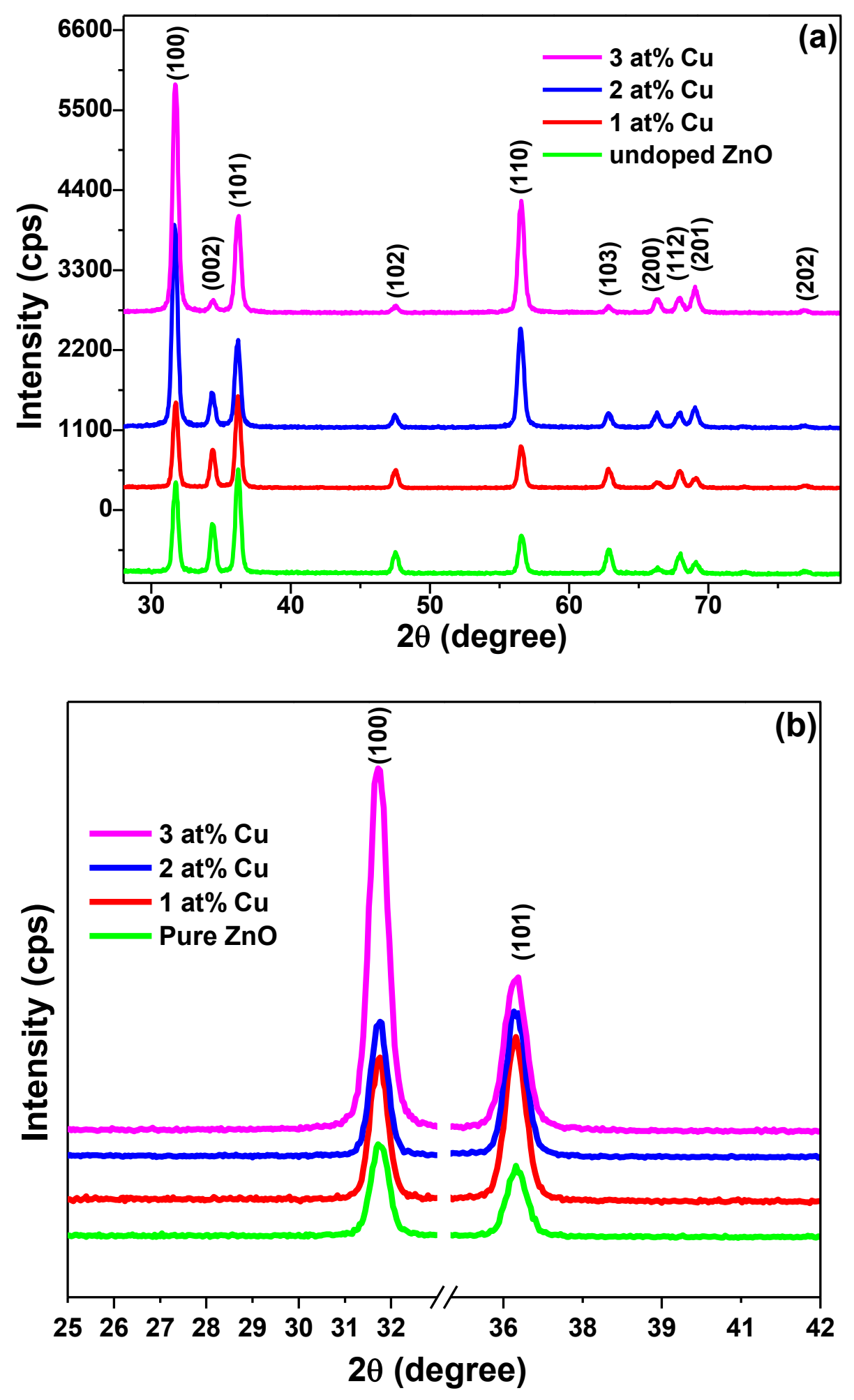

Fig. 1. $\mathrm{XRD}$ spectra of undoped and $\mathrm{Cu}$ doped $\mathrm{ZnO}$ nanorods (a) and the extended diffraction peaks showing broadening of (100) and (101) planes (b). 


$$
\begin{aligned}
& a=\sqrt{\frac{1}{3}} \frac{\lambda}{\sin \theta} \\
& c=\frac{\lambda}{\sin \theta}
\end{aligned}
$$

where $\lambda$ is the wavelength of the incident $\mathrm{X}$-ray beam and $\theta$ is the diffraction angle. The calculated values of both $a$ and $c$ decreased with increased $\mathrm{Cu}$ doping as compared to standard values for $\mathrm{ZnO}$ bulk a $=3.249$ and $\mathrm{c}=5.206 \AA$. The decrease in lattice parameters is due to the $\mathrm{Cu}^{2+}$ ions having a substitutionally smaller ionic radius of $0.057 \mathrm{~nm}$ compared to the host $\mathrm{Zn}^{+2}$ ions having ionic radius of $0.074 \mathrm{~nm}$ [17] and evidences substitution of $\mathrm{Cu}^{2+}$, not $\mathrm{Cu}^{+}$ions having $0.096 \mathrm{~nm}$. The volume of the unit cell was calculated using equation (3).

$$
V=\frac{\sqrt{3} a^{2} c}{2}
$$

where $V$ is the volume of unit cell. The result reveals a decreased volume of the cell as a result of incorporation of $\mathrm{Cu}$ into the $\mathrm{ZnO}$ lattice. For further investigation on the effects of $\mathrm{Cu}$ doping concentration in the structure of $\mathrm{ZnO}$ nanorods, average crystallite size, $\mathrm{D}$, were calculated using Scherrer's equation 4, shown in table 1. The crystallite size increased initially from $19.516 \mathrm{~nm}$ for undoped to $19.524 \mathrm{~nm}$ for 1 at $\% \mathrm{Cu}$ doped $\mathrm{ZnO}$. Subsequent increased in the $\mathrm{Cu}$ concentration lead to a significant decrease in the crystallite size.

$$
D=\frac{0.9 \lambda}{\beta \cos \theta}
$$

Since it is observed that there was a change lattice parameters with increased $\mathrm{Cu}$ doping, crystal lattice distortion degree $R$ and $\mathrm{Zn}-\mathrm{O}$ bond length $L$ were calculated using equations (5) and (6), respectively [25]. 


$$
\begin{gathered}
R=\frac{2 a \sqrt{2}}{3 c} \\
L=\sqrt{\left(\frac{a^{2}}{3}+\left(\frac{1}{2}-u\right)^{2} c^{2}\right)}
\end{gathered}
$$

where $u$ is the positional parameter in the wurtzite structure given by the following expression:

$$
u=\frac{a^{2}}{3 c^{2}}+0.25
$$

\begin{tabular}{|c|c|c|c|c|c|c|}
\hline \multirow[t]{2}{*}{ Sample } & \multicolumn{2}{|c|}{$\begin{array}{c}\text { Lattice } \\
\text { parameters }(\AA)\end{array}$} & \multirow{2}{*}{$\begin{array}{c}\text { Volume of } \\
\text { unit cell } \\
\left(\AA^{3}\right)\end{array}$} & \multirow{2}{*}{$\begin{array}{c}\text { Average } \\
\text { crystallite size, } \\
\text { D (nm) }\end{array}$} & \multirow{2}{*}{$\begin{array}{l}\text { crystal lattice } \\
\text { distortion } \\
\text { degree, } R\end{array}$} & \multirow[t]{2}{*}{$\begin{array}{c}\text { Bond } \\
\text { length }(\AA)\end{array}$} \\
\hline & $a$ & $c$ & & & & \\
\hline $\begin{array}{l}\text { Undoped } \\
\mathrm{ZnO}\end{array}$ & 3.2547 & 5.2098 & 47.7929 & 19.516 & 0.5889 & 1.9802 \\
\hline 1 at $\% \mathrm{Cu}$ & 3.1350 & 5.2157 & 44.3924 & 19.524 & 0.5889 & 1.9320 \\
\hline 2 at $\% \mathrm{Cu}$ & 3.1309 & 5.2098 & 44.2263 & 19.033 & 0.5665 & 1.9296 \\
\hline 3 at $\% \mathrm{Cu}$ & 3.1295 & 5.2039 & 44.1370 & 18.455 & 0.5669 & 1.9283 \\
\hline
\end{tabular}

Table 1. Lattice parameters, volume of unit cell, average crystallite size, crystal lattice distortion degree and bond length of undoped and $\mathrm{Cu}$ doped $\mathrm{ZnO}$ nanorods.

The obtained crystal lattice distortion degree and $\mathrm{Zn}-\mathrm{O}$ bond length are shown in Table 1. It is observed that the $\mathrm{Zn}-\mathrm{O}$ bond length of undoped sample is slightly longer than the reported one $1.9767 \AA$ [26]. For doped samples, the $\mathrm{Zn}-\mathrm{O}$ bond length in the unit cell of $\mathrm{ZnO}$ is observed to decrease with increased $\mathrm{Cu}$ concentration. This is caused by the incorporation of $\mathrm{Cu}$ into $\mathrm{ZnO}$ lattice which causes a change in the lattice parameters.

The morphology of undoped $\mathrm{ZnO}$ and $\mathrm{Cu}$ doped $\mathrm{ZnO}$ were observed and the micrographs are displayed in Fig. 2. The undoped sample Fig. 2 (a) shows well defined nanorods having flat hexagonal shape with diameter ranging from 82 to $120 \mathrm{~nm}$. Fig. 2 (b) shows slight changes in the 
hexagonal shape of the nanorods with diameters ranging from 60 to $130 \mathrm{~nm}$. Fig. 2 (c) and (d) show significant deviation from the undoped sample, indicating that $\mathrm{Cu}$ has incorporated into $\mathrm{ZnO}$ lattice.
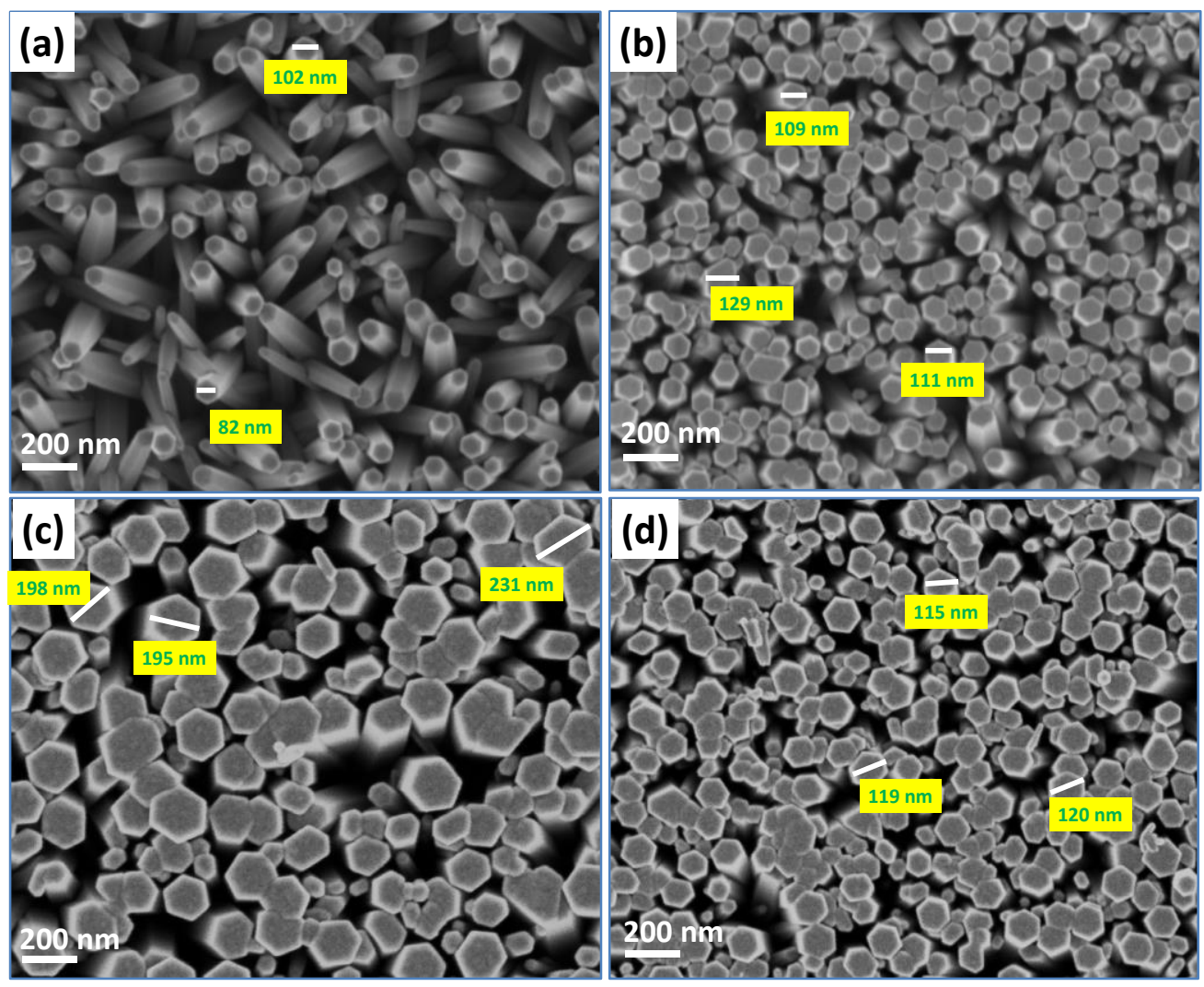

Fig. 2. FESEM micrographs showing (a) undoped $\mathrm{ZnO}$ nanorods, (b) $\mathrm{Cu}$ doped $\mathrm{ZnO} 1$ at.\%, (c) 2 at.\% and (d) 3at.\%

The average diameter increased to $\sim 210 \mathrm{~nm}$ for 2 at. $\%$ which then decreased to $\sim 115 \mathrm{~nm}$ for 3 at.\% $\mathrm{Cu}$ doping. Some of the nanorods doped with 2 at.\% and 3 at.\% of $\mathrm{Cu}$ aggregated became compact, forming distorted hexagonal shapes. This is more pronounced in 3 at. $\% \mathrm{Cu}$ doped $\mathrm{ZnO}$ nanorods. This can be attributed to $\mathrm{pH}$ changes of growth solution as measured 7.64, 7.03, 6.83 and 6.77 for undoped, 1, 2, and 3 at.\% $\mathrm{Cu}$ doped $\mathrm{ZnO}$, respectively. From this trend, it is clear that addition of $\mathrm{Cu}$ lowers the $\mathrm{pH}$ and hence changes supersaturation nature of the growth 
solution which affects the nucleation rate and crystal growth of the nanorods. Zhang et al [27] and Desai and Sartale [28] reported that, it is the degree of supersaturation that controls growth rate and orientation of $\mathrm{ZnO}$ nanorods. It can be concluded that, addition of $\mathrm{Cu}$ changes the growth environment by lowering the $\mathrm{pH}$ of the growth solution.

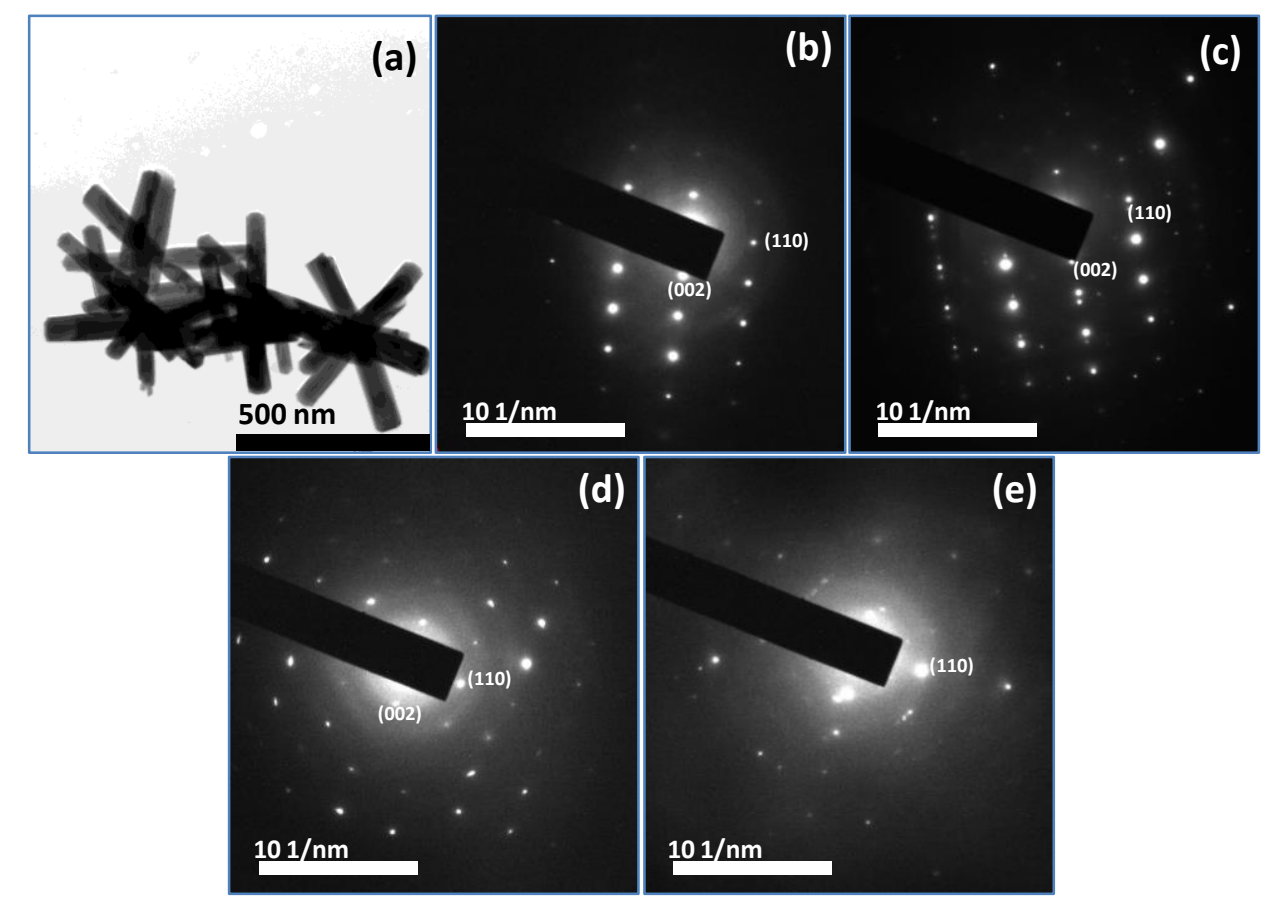

Fig. 3. (a) and (b) TEM image and its corresponding SAED patterns of undoped (pure) $\mathrm{ZnO}$ nanorods, (c), (d) and (e) show SAED patterns of 1, 2 and 3 at \% $\mathrm{Cu}$ doped $\mathrm{ZnO}$.

Fig. 3 (a) shows a TEM image of an undoped sample revealing rod like structures which confirmed in SEM images of Fig. 2. The selected area electron diffraction (SAED) pattern of undoped and $\mathrm{Cu}$ doped $\mathrm{ZnO}$ are shown in Fig. 3 (b) to (e). In view of SAED patterns it is clear that the obtained samples are of high quality, single crystalline wurtzite structure of $\mathrm{ZnO}$ which matches well with the XRD results in Fig. 1. Further observation of the SAED patterns indicate that the intensities of bright spots varies with $\mathrm{Cu}$ doping demonstrating different crystallite sizes of synthesized nanorods where-by the 3 at $\% \mathrm{Cu}$ doped sample displays broader spots. This is 
clearly indicated by (002) and (110) planes where the intensities of bright spots decreased for (002) and increased for (110) with $\mathrm{Cu}$ doping. This observation is in agreement with XRD results. The undoped sample displays sharp spots representing different diffraction planes and the sharpness of the spots decreases with increasing $\mathrm{Cu}$ doping, indicating deterioration of crystallinity.

\subsection{Optical properties}

The UV-visible absorption spectra of both undoped and $\mathrm{Cu}$-doped $\mathrm{ZnO}$ nanorods are shown in Fig. 4. The observed absorption band edges were 375, 378, 380 and $379 \mathrm{~nm}$ for samples undoped, 1, 2, and 3 at.\% $\mathrm{Cu}$ doped $\mathrm{ZnO}$ nanorods, respectively. A red shift in band edge absorption peak was observed with increased $\mathrm{Cu}$ content. This shift in band edge to lower energy can be ascribed due to the $p$ - $d$ exchange interactions amongst the band electrons and localized $d$ electrons of $\mathrm{Cu}^{2+}$ ions substituting $\mathrm{Zn}^{2+}$ ions as previously reported for doped $\mathrm{ZnO}$ nanostructures $[23,29]$. This exchange interaction causes valence band to advance upwards while lowering conduction band resulting in decreased band gap energy. 


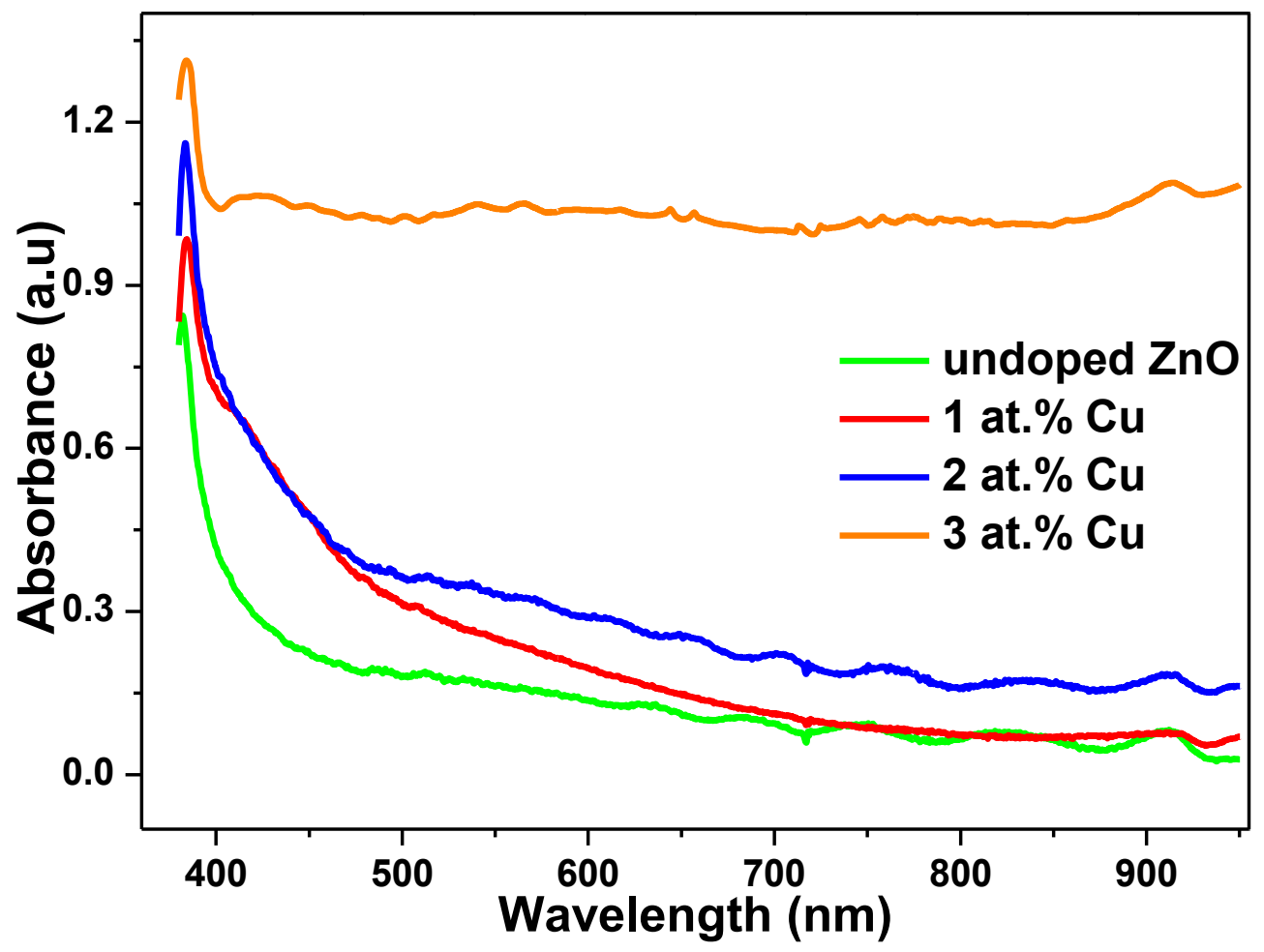

Fig. 4. Optical absorption spectra of undoped and $\mathrm{Cu}$ doped $\mathrm{ZnO}$ nanorods

\subsection{Raman Studies}

Raman studies were conducted to investigate the effects of $\mathrm{Cu}$ doping in the vibration modes of $\mathrm{ZnO}$ nanorods. Wurtzite structure of $\mathrm{ZnO}$ comprises phonon modes belonging to $2 \mathrm{E}_{1}, 2 \mathrm{E}_{2}, 2 \mathrm{~A}_{1}$ and $2 \mathrm{~B}_{1}$ with $\mathrm{B}_{1}$ symmetry modes are silent (Raman inactive). Polar $\mathrm{A}_{1}$ and $\mathrm{E}_{1}$ phonon modes are divided into two optical modes: transverse optical (TO) and longitudinal optical (LO) and non-polar $\mathrm{E} 2$ is separated into $\mathrm{E}_{2}$ (high) and $\mathrm{E}_{2}$ (low) [30]. Fig. 5 shows room temperature Raman spectra of pure and $\mathrm{Cu}$ doped $\mathrm{ZnO}$ nanorods. The observed Raman modes include $\mathrm{E}_{2}$ (low) at $99 \mathrm{~cm}^{-1}, \mathrm{E}_{2}$ (high) $-\mathrm{E}_{2}$ (low) at about $332 \mathrm{~cm}^{-1}, \mathrm{~A}_{1}(\mathrm{TO})$ at $381 \mathrm{~cm}^{-1}, \mathrm{E}_{2}$ (high) at 438 $\mathrm{cm}^{-1}$ and $\mathrm{E}_{1}(\mathrm{LO})$ at $583 \mathrm{~cm}^{-1}$. The strong and sharp $\mathrm{E}_{2}$ (low) and $\mathrm{E}_{2}$ (high) optical phonon peaks at $99 \mathrm{~cm}^{-1}$ and $438 \mathrm{~cm}^{-1}$ which correspond to the vibrations of zinc sub-lattice and oxygen atoms, 
respectively, are observed in all Raman spectra. This confirms wurtzite crystal structure of $\mathrm{ZnO}$ as shown in XRD and TEM results.

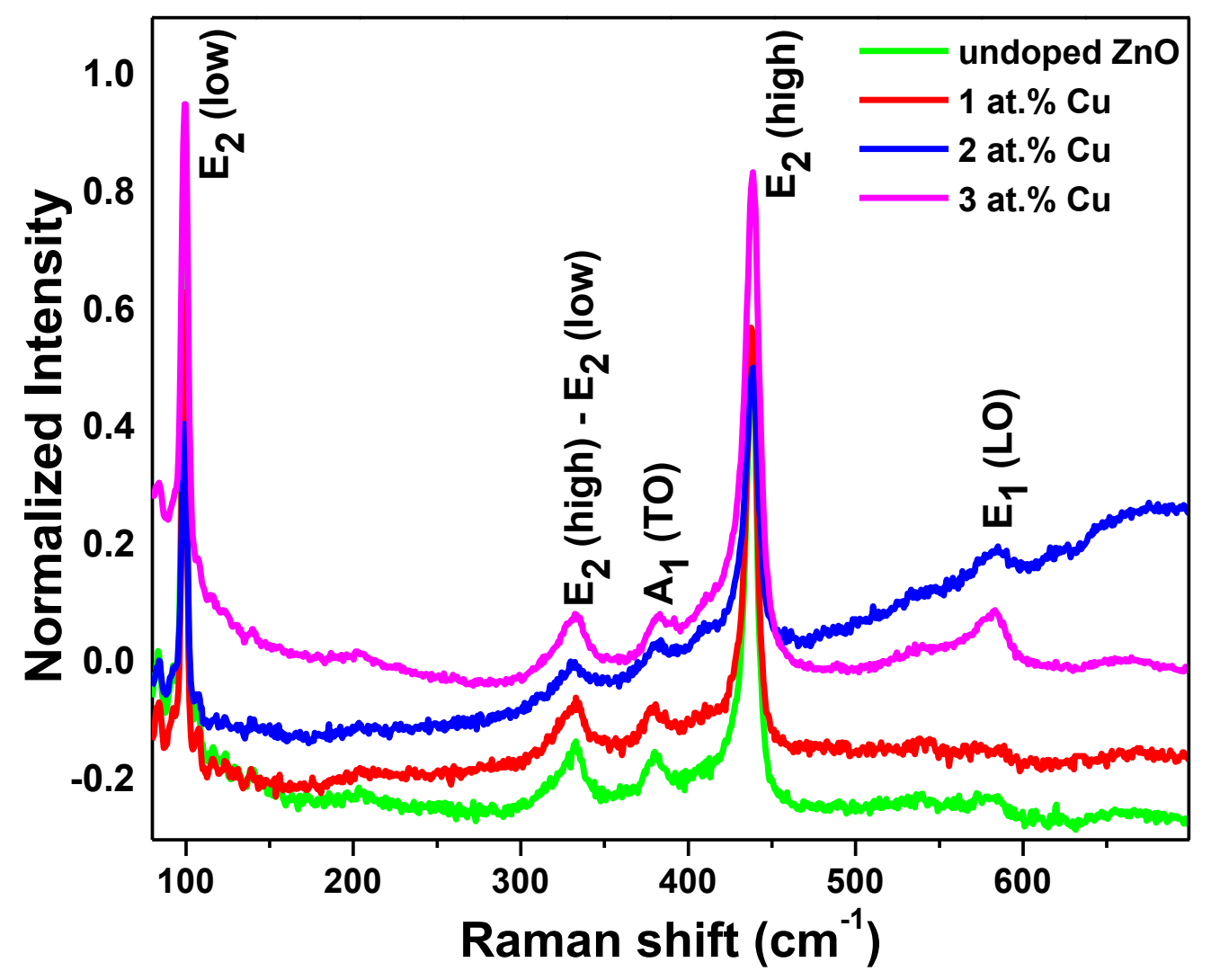

Fig. 5. Room temperature Raman spectra of undoped and $\mathrm{Cu}$ doped $\mathrm{ZnO}$ nanorods.

Josh et al [18] found that incorporation of $\mathrm{Cu}$ into $\mathrm{ZnO}$ lattice leads to the evolution of $\mathrm{LO}$ phonon modes. This is clearly observed in our study where-by the intensity of $E_{1}$ (LO) peak at $583 \mathrm{~cm}^{-1}$ which is related to the formation of defects in $\mathrm{ZnO}$ crystal increased with increase $\mathrm{Cu}$ dopant and is more pronounced for the nanorods with 2 at. $\%$ and 3 at.\% $\mathrm{Cu}$. This indicates incorporation of $\mathrm{Cu}$ into $\mathrm{ZnO}$ lattice which activated the vibrational frequency of oxygen sublattices in $\mathrm{ZnO}$ due to the presence of defects. Furthermore, the intensity ratios for $\mathrm{E}_{1}$ (LO) to $\mathrm{E}_{2}$ (high) $\left(\left(E_{1}(L O) / E_{2}(\right.\right.$ high $\left.)\right)$ initially decreased from 0.08 to 0.063 for undoped sample and 1 
at.\% $\mathrm{Cu}$ doped, respectively, then increased with increasing $\mathrm{Cu}$ dopant to 0.115 and 0.121 for 2 and 3 at.\% $\mathrm{Cu}$ doped $\mathrm{ZnO}$ nanorods, respectively. This substantiates the increased amount of defects with increase in $\mathrm{Cu}$ doping and thus suggests that there is an increase in oxygen vacancies. This agrees well with the results reported by Zhang et al [27] who stated that the higher intensities ratio of $\mathrm{E}_{1}(\mathrm{LO}) / \mathrm{E}_{2}$ (high) the higher the number of defects in $\mathrm{ZnO}$ lattice. Jäppinen et al [31] reported decreased FWHM values of $\mathrm{E}_{1}$ (low) after heat treatment and thus reduced the disorder in Zn sub-lattice. In the present study, FWHM of the $\mathrm{E}_{2}$ (low) and $\mathrm{E}_{2}$ (high) peaks increased with increasing $\mathrm{Cu}$ doping. This observation may be due to the incorporation of $\mathrm{Cu}$ in the $\mathrm{Zn}$ sublattice which leads to the observed increased lattice distortion. The effect of $\mathrm{Cu}$ doping concentration on the optical capability of the nanorods was further investigated by calculating effective phonon energy $\left(E_{\mathrm{ph}}\right) \mathrm{cm}^{-1}$ using phonon mode position $\left(E_{\mathrm{i}}\right) \mathrm{cm}^{-1}$, FWHM $\left(\beta_{\mathrm{i}}\right) \mathrm{cm}^{-1}$ and intensities $\left(I_{\mathrm{i}}\right)$ of each corresponding peak using equation below [32].

$$
E_{p h}=\frac{\sum_{i} E_{i} \beta_{i} I_{i}}{\sum_{i} \beta_{i} I_{i}}
$$

The lower the effective phonon energy the better the sample is in terms of its optical application as it has been reported by Das et al. [32]. The authors reported that lower effective phonon energy minimizes multiphonon losses. In our study, the obtained values of effective phonon energy were $342,331,394$ and $366 \mathrm{~cm}^{-1}$, for undoped, 1 at.1\%, 2 at.\% and 3 at.\% $\mathrm{Cu}$ doped $\mathrm{ZnO}$ nanorods, respectively. The trend is clear according to the Fig. 5 where increased $\mathrm{Cu}$ doping increases the intensity of $\mathrm{E}_{1}(\mathrm{LO})$ peak at $583 \mathrm{~cm}^{-1}$ resulting in an increased $E_{\mathrm{ph}}$ for 2 at.\% and 3 at.\% $\mathrm{Cu}$ doped samples.

\subsection{Electrical Characterization}


Fig. 6 shows the measured $I-V$ characteristics (semi-log scale) of the undoped $\mathrm{ZnO}$ nanorods and variously doped with $\mathrm{Cu}$. The insert clearly demonstrates that the ITO substrate is ohmic. The curves show improving rectification behavior, positively correlated to the increasing $\mathrm{Cu}$ doping: the 3 at.\% sample's reverse leakage current is almost two orders of magnitude better than that for undoped $\mathrm{ZnO}$ nanorods. The contrast between forward and reverse current measured at $\pm 2 \mathrm{~V}$ applied voltage is about four orders of magnitude, indicating progressive improvements in rectifying behaviour of the Schottky device.

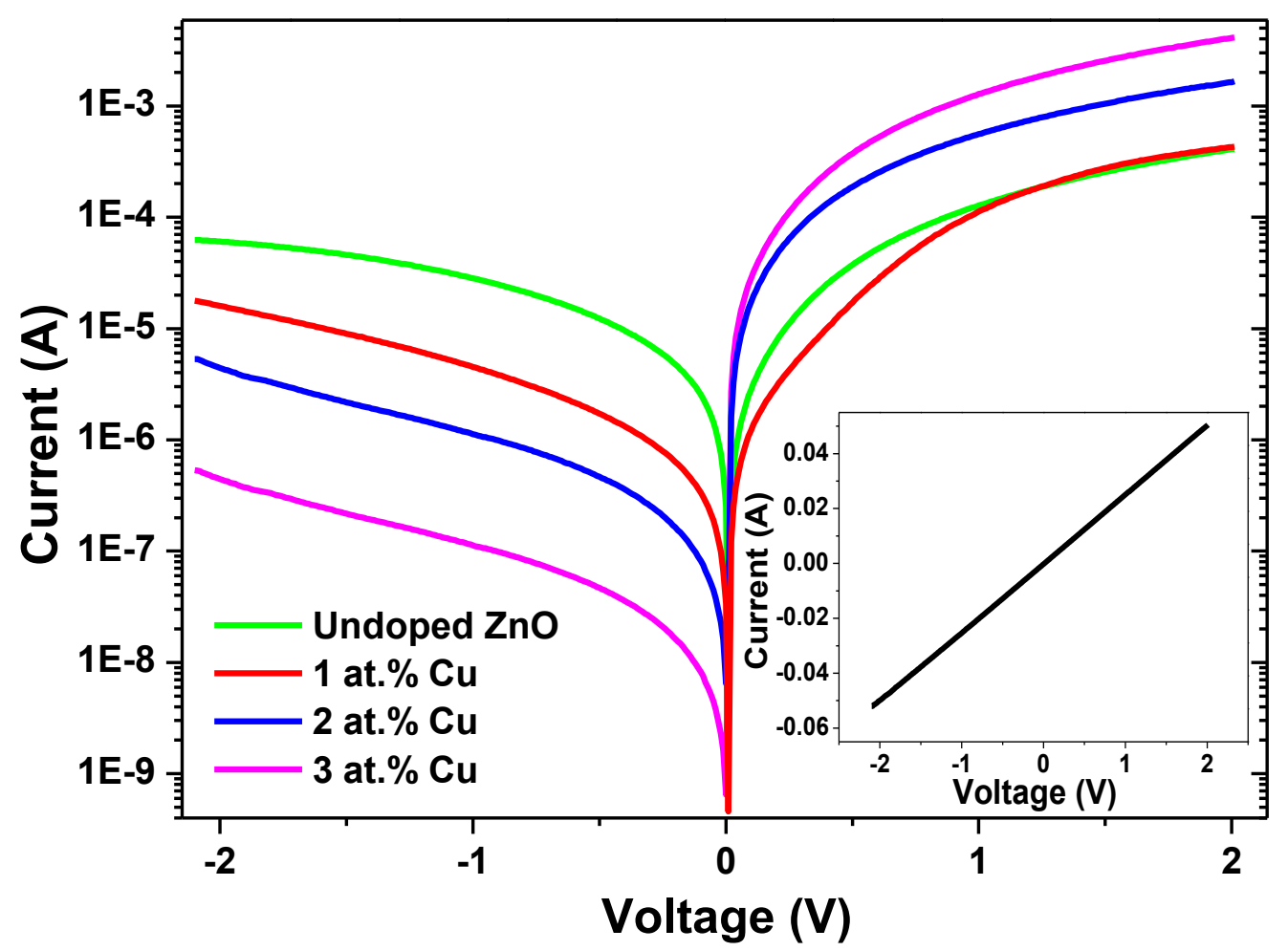

Fig. 6. Semi-logarithmic $I-V$ characteristics of undoped and $\mathrm{Cu}$ doped $\mathrm{ZnO}$ nanorods. The insert shows linear $I-V$ characteristics of ITO substrate ohmic contact.

According to the thermionic emission theory, the forward voltage $I-V$ characteristics of a Schottky diode with series resistance, $\mathrm{R}_{\mathrm{S}}$, can be described by the relation: 


$$
I=I_{0}\left\{1-\exp \left[-q\left(V-I R_{S}\right) / k_{\mathrm{B}} T\right]\right\}
$$

with, $I_{0}$, the saturation current, given by:

$$
I_{0}=S A^{*} T^{2} \exp \left(-q \Phi_{B 0} / n k_{\mathrm{B}} T\right)
$$

$\Phi_{B 0}$ is the zero bias Schottky barrier height, $S$ the diode metal contact area and the ideality factor, $n$ is an indicator of linearity in the $I-V$ characteristics and is given by:

$$
\frac{1}{n}=\frac{k_{B} T}{q} \frac{d \ln I}{d V}
$$

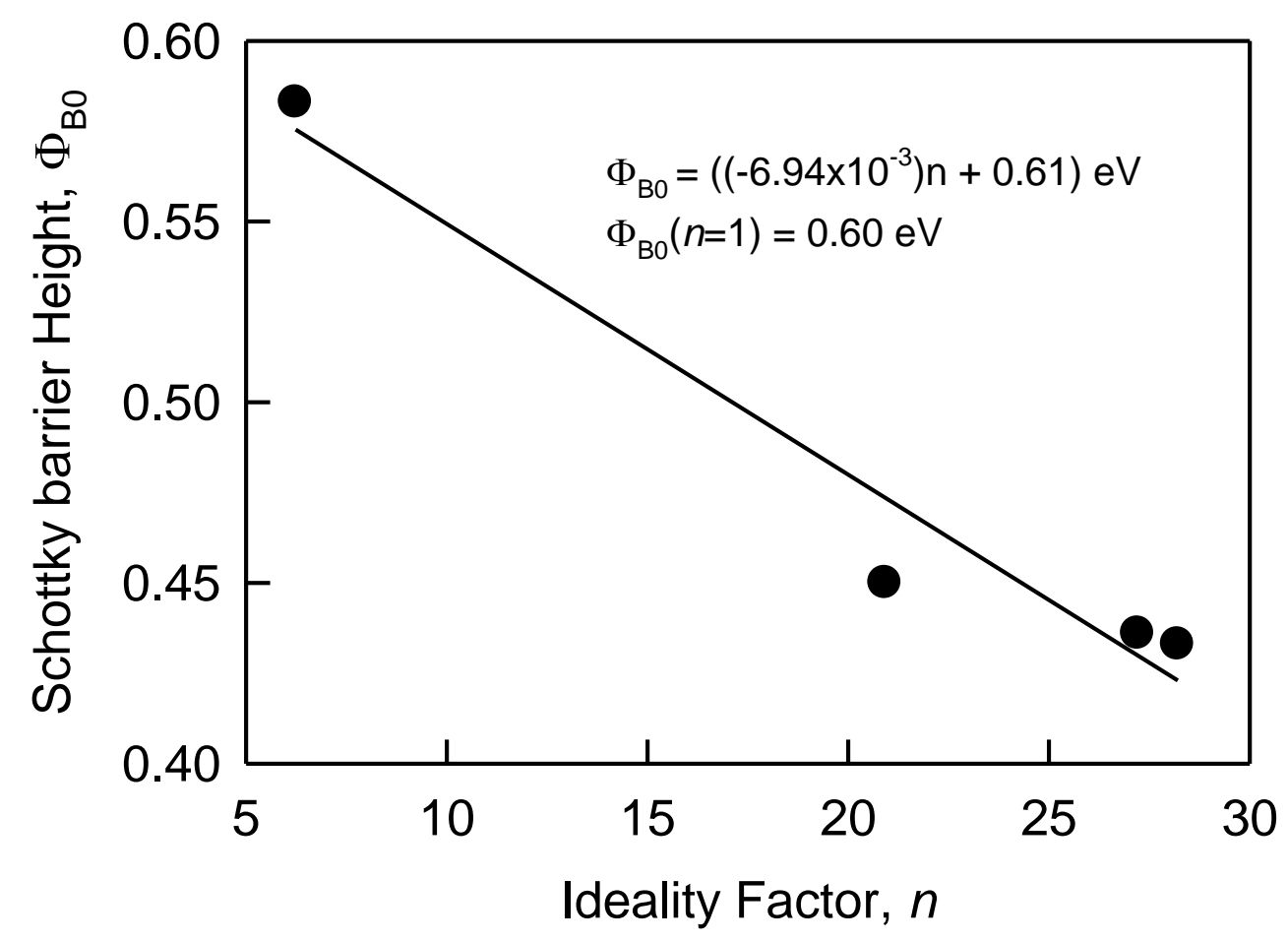

Fig. 7. Relationship between Schottky barrier height and ideality factor

The nanorods underneath the Au metal could be considered as a collection of individual Schottky diodes connected in parallel. Plotting $\Phi_{\mathrm{B} 0}$ versus $n$ should yield a straight line, according to Schmitzdorpf et al [33] Fig. 7. This model predicts a Schottky barrier height of $0.60 \mathrm{eV}$ for an 
ideal thermionic device with $n=1$. This is not far off from the theoretical Schottky-Mott value of $0.80 \mathrm{eV}$, the difference between the Au work-function and the $\mathrm{ZnO}$ nanorods electron affinity of $4.27 \mathrm{eV}$. The deviation could be accounted for by, amongst others, the deteriorating crystalline quality of the nanorods accompanying the increased $\mathrm{Cu}$ doping, shown earlier herein and departure from linearity of the $I-V$ characteristics, particularly at 2 and 3 at.\% Cu doping. In conclusion, the $I-V$ characterization indicates that the incorporated $\mathrm{Cu}$ is electrically active with potentially better rectifying devices possible at higher $\mathrm{Cu}$ doping.

\section{Conclusion}

In summary, undoped and $\mathrm{Cu}$ doped $\mathrm{ZnO}$ nanorods were synthesized on ITO substrates by $\mathrm{CBD}$ technique. The effects of $\mathrm{Cu}$ doping content on structural, morphological, optical and electrical properties were systematically observed. XRD results showed changes in the various structural parameters of $\mathrm{ZnO}$ nanorods indicating incorporation of $\mathrm{Cu}^{2+}$ into $\mathrm{ZnO}$ lattice. Sharp and clear diffraction spots were observed for undoped $\mathrm{ZnO}$ nanorods indicating that the synthesized $\mathrm{ZnO}$ nanorods have a good single-crystalline structure which then decreased with $\mathrm{Cu}$ doping. The lattice parameters decreased with increased $\mathrm{Cu}$ doping. The absorption and Micro Raman measurement revealed that $\mathrm{Cu}$ doping affects the absorption and vibration properties of the synthesized $\mathrm{ZnO}$ nanorods. The intensity of $\mathrm{E}_{1}$ (LO) peak at $583 \mathrm{~cm}^{-1}$ which is related to the formation of defects in $\mathrm{ZnO}$ crystal increased with increasing $\mathrm{Cu}$ content and is more pronounced for the nanorods with 2 at. $\%$ and 3 at. $\% \mathrm{Cu}$ indicating incorporation of $\mathrm{Cu}$ into $\mathrm{ZnO}$ lattice. The $I-V$ curve clearly show improving rectification positively correlated to the increasing $\mathrm{Cu}$ doping: the $2 \%$ sample's reverse leakage current is almost two orders of magnitude better than that for undoped nanorods. 


\section{Acknowledgements}

The work was financially supported by the University of Pretoria and National Research

Foundation (NRF), South Africa, Grant No: 91550 and 94166. The authors acknowledge Pontsho Mbule of the University of South Africa (UNISA) for the XRD measurement.

\section{References}

[1] O.D. Jayakumar, V. Sudarsan, A.K. Tyagi, Template-assisted synthesis of roomtemperature ferromagnetic Mn-doped ZnO: First example of a high-temperature synthesis using polystyrene, Cryst. Growth Des. 9 (2009) 1944-1948. doi:10.1021/cg801182q.

[2] G. Wrobel, M. Piech, P.-X. Gao, S. Dardona, Direct Synthesis of ZnO Nanorod Field Emitters on Metal Electrodes, Cryst. Growth Des. 12 (2012) 5051-5055. doi:10.1021/cg301002s.

[3] J. Lu, Z. Shi, Y. Wang, Y. Lin, Q. Zhu, Z. Tian, et al., Plasmon-enhanced Electrically Light-emitting from ZnO Nanorod Arrays/p-GaN Heterostructure Devices, Sci. Rep. 6 (2016) 25645. doi:10.1038/srep25645.

[4] B. Kumar, S.W. Kim, Energy harvesting based on semiconducting piezoelectric ZnO nanostructures, Nano Energy. 1 (2012) 342-355. doi:10.1016/j.nanoen.2012.02.001.

[5] S.H. Oh, S.J. Heo, J.S. Yang, H.J. Kim, E ff ects of ZnO Nanoparticles on P3HT : PCBM Organic Solar Cells with DMF-Modulated PEDOT : PSS Bu ff er Layers, (2013).

[6] M. Zi, M. Zhu, L. Chen, H. Wei, X. Yang, B. Cao, ZnO photoanodes with different morphologies grown by electrochemical deposition and their dye-sensitized solar cell properties, Ceram. Int. 40 (2014) 7965-7970. doi:10.1016/j.ceramint.2013.12.146.

[7] N. Sinha, G. Ray, S. Bhandari, S. Godara, B. Kumar, Synthesis and enhanced properties of cerium doped $\mathrm{ZnO}$ nanorods, Ceram. Int. 40 (2014) 12337-12342. 
doi:10.1016/j.ceramint.2014.04.079.

[8] Z. Chen, N. Zhang, Y.-J. Xu, Synthesis of graphene-ZnO nanorod nanocomposites with improved photoactivity and anti-photocorrosion, CrystEngComm. 15 (2013) 3022. doi:10.1039/c3ce27021a.

[9] H. Wang, M. Qiong, H. Niu, X. Mao, L. Wan, X. Jinzhang, et al., Molecular Nanotechnology Hydrothermal Growth of Aligned ZnO Nanorods along the Seeds Prepared by Magnetron Sputtering and its Applications in Quantum Dots, J Nanomater Mol Nanotechnol. 2 (2013) 1-5.

[10] V. Gaddam, R.R. Kumar, M. Parmar, M.M. Nayak, K. Rajanna, Synthesis of ZnO nanorods on a flexible Phynox alloy substrate: influence of growth temperature on their properties, RSC Adv. 5 (2015) 89985-89992. doi:10.1039/C5RA12773D.

[11] M.Y. Cho, M.S. Kim, S. Kim, J.-Y. Leem, D.Y. Kim, S.-O. Kim, et al., Fabrication and photoluminescence studies of porous ZnO nanorods, J. Korean Phys. Soc. 61 (2012) 102107. doi:10.3938/jkps.61.102.

[12] H. Wang, Q. Ma, H. Niu, X. Mao, L. Wan, J. Xu, et al., Molecular Nanotechnology Hydrothermal Growth of Aligned ZnO Nanorods along the Seeds Prepared by Magnetron Sputtering and its Applications in Quantum Dots, J. Nanomater. Mol. Nanotechnol. 2 (2013) 1-5.

[13] C. Hsu, L. Chen, X. Zhang, Effect of the Cu Source on Optical Properties of CuZnO Films Deposited by Ultrasonic Spraying, (2014) 1261-1270. doi:10.3390/ma7021261.

[14] Y.R. Uhm, B. Sun Han, C.K. Rhee, S.J. Choi, Photocatalytic characterization of Fe-and Cu-doped ZnO nanorods synthesized by cohydrolysis, J. Nanomater. 2013 (2013) 1-7. doi:10.1155/2013/958586. 
[15] C. Mao, L. Fang, H. Zhang, W. Li, F. Wu, G. Qin, et al., Effect of B doping on optical, electrical properties and defects of ZnO films, J. Alloys Compd. 676 (2016) 135-141. doi:10.1016/j.jallcom.2016.03.157.

[16] Y. Wang, Y. Han, J. Han, X. Zhang, Y. Chen, S. Wang, et al., UV-free red electroluminescence from the cross- connected $\mathrm{p}-\mathrm{ZnO}: \mathrm{Cu}$ nanobushes / n-GaN light emitting diode, 24 (2016) 2182-2188. doi:10.1364/OE.24.003940.

[17] M. Babikier, D. Wang, J. Wang, Q. Li, J. Sun, Y. Yan, et al., Cu-doped ZnO nanorod arrays: the effects of copper precursor and concentration., Nanoscale Res. Lett. 9 (2014) 199. doi:10.1186/1556-276X-9-199.

[18] K. Joshi, M. Rawat, S.K. Gautam, R.G. Singh, R.C. Ramola, F. Singh, Band gap widening and narrowing in Cu-doped $\mathrm{ZnO}$ thin films, J. Alloys Compd. 680 (2016) 252-258. doi:10.1016/j.jallcom.2016.04.093.

[19] S. Muthukumaran, R. Gopalakrishnan, Structural, FTIR and photoluminescence studies of $\mathrm{Cu}$ doped ZnO nanopowders by co-precipitation method, 34 (2012) 1946-1953. doi:10.1016/j.optmat.2012.06.004.

[20] C.H. Hsu, L.C. Chen, X. Zhang, Effect of the cu source on optical properties of CuZnO films deposited by ultrasonic spraying, Materials (Basel). 7 (2014) 1261-1270. doi:10.3390/ma7021261.

[21] D. Sahu, N.R. Panda, B.S. Acharya, A.K. Panda, Microstructural and optical studies on sonochemically synthesized $\mathrm{Cu}$ doped $\mathrm{ZnO}$ nanoparticles, AIP Conf. Proc. 1591 (2014) 276-278. doi:10.1063/1.4872571.

[22] S. Singhal, J. Kaur, T. Namgyal, R. Sharma, Cu-doped ZnO nanoparticles: Synthesis, structural and electrical properties, Phys. B Condens. Matter. 407 (2012) 1223-1226. 
doi:10.1016/j.physb.2012.01.103.

[23] A.A. Othman, M.A. Ali, E.M.M. Ibrahim, M.A. Osman, Influence of Cu doping on structural, morphological, photoluminescence, and electrical properties of $\mathrm{ZnO}$ nanostructures synthesized by ice-bath assisted sonochemical method, J. Alloys Compd. 683 (2016) 399-411. doi:10.1016/j.jallcom.2016.05.131.

[24] L. Agarwal, B.K. Singh, S. Tripathi, P. Chakrabarti, Fabrication and characterization of $\mathrm{Pd} / \mathrm{Cu}$ doped $\mathrm{ZnO} / \mathrm{Si}$ and $\mathrm{Ni} / \mathrm{Cu}$ doped $\mathrm{ZnO} / \mathrm{Si}$ Schottky diodes, Thin Solid Films. 612 (2016) 259-266. doi:10.1016/j.tsf.2016.06.027.

[25] P. Chand, A. Gaur, A. Kumar, U.K. Gaur, Effect of NaOH molar concentration on optical and ferroelectric properties of $\mathrm{ZnO}$ nanostructures, Appl. Surf. Sci. 356 (2015) 438-446. doi:10.1016/j.apsusc.2015.08.107.

[26] M.A. Gaikwad, M.P. Suryawanshi, S.S. Nikam, C.H. Bhosale, J.H. Kim, A. V. Moholkar, Influence of $\mathrm{Zn}$ concentration and dye adsorption time on the photovoltaic performance of M-SILAR deposited ZnO-based dye sensitized solar cells, J. Photochem. Photobiol. A Chem. 329 (2016) 246-254. doi:10.1016/j.jphotochem.2016.07.006.

[27] D.F. Zhang, L.D. Sun, J. Zhang, Z.G. Yan, C.H. Yan, Hierarchical construction of ZnO architectures promoted by heterogeneous nucleation, Cryst. Growth Des. 8 (2008) 36093615. doi:10.1021/cg800143x.

[28] M.A. Desai, S.D. Sartale, Facile soft solution route to engineer hierarchical morphologies of ZnO nanostructures, Cryst. Growth Des. 15 (2015) 4813-4820. doi:10.1021/acs.cgd.5b00561.

[29] S. Maensiri, P. Laokul, S. Phokha, A simple synthesis and magnetic behavior of nanocrystalline $\mathrm{Zn} 0.9 \mathrm{Co} 0.1 \mathrm{O}$ powders by using $\mathrm{Zn}$ and Co acetates and polyvinyl 
pyrrolidone as precursors, J. Magn. Magn. Mater. 305 (2006) 381-387.

doi:10.1016/j.jmmm.2006.01.115.

[30] R. Sánchez Zeferino, M. Barboza Flores, U. Pal, Photoluminescence and raman scattering in ag-doped zno nanoparticles, J. Appl. Phys. 109 (2011) 1-7. doi:10.1063/1.3530631.

[31] L. Jäppinen, T. Jalkanen, B. Sieber, A. Addad, M. Heinonen, E. Kukk, et al., Enhanced Photoluminescence in Acetylene-Treated ZnO Nanorods, Nanoscale Res. Lett. 11 (2016) 413. doi:10.1186/s11671-016-1627-y.

[32] R. Das, A. Kumar, Y. Kumar, S. Sen, P.M. Shirage, Effect of growth temperature on the optical properties of $\mathrm{ZnO}$ nanostructures grown by simple hydrothermal method, RSC Adv. 5 (2015) 60365-60372. doi:10.1039/C5RA07135F.

[33] R.F. Schimitsdorf, T.U. Kampen, W. Monch, Explanation of the linear correlation between barrier heights and ideality factors of real metal-semiconductor contacts by laterally nonuniform Schottky barriers, J. Vac. Sci Technol. B. 15 (1997) 1221-1226. 